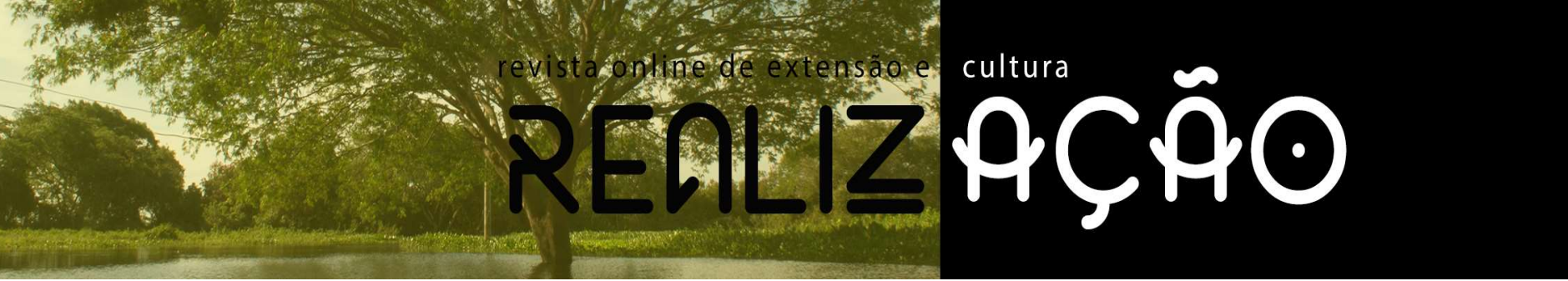

\title{
TRANSFERÊNCIA DE TECNOLOGIAS ZOOTÉCNICAS A AGRICULTORES FAMILIARES NO MUNICÍPIO DE ESPINOSA/MG
}

Technology Transfer Zootechnical to Farmers Family of Espinosa/MG

DOI: 10.30612/re-ufgd.v6i11.8198

Flávio Pinto Monção $^{1}$
José Márcio Alkimin $^{2}$
João Paulo Sampaio Rigueira
Daniella Cangussú Tolentino
${ }^{3}$
Instituto Superior de Educação Verde Norte (Favenorte) Vicente Ribeiro Rocha júnior $^{1}$
Julieta Maria Alencar Chamone $^{1}$
Cinara da Cunha Siqueira Carvalho
Orlando Felipe Costa Marques $^{1}$
Jozelia Aparecida Ribeiro de Melo
Marcos Felipe Pereira da Silva

Recebido: 30/05/2019

Aceito: $18 / 10 / 2019$

Resumo - objetivou-se por meio de atividades extensionistas orientar e incentivar produtores da agricultura familiar do município de espinosa quanto ao uso de tecnologias de forma estratégica visando aumentar a produção de leite e/ou carne ao longo do ano. O desenvolvimento das ações para os produtores familiares da região de Espinosa-MG foi realizado a partir de Julho de 2017. A princípio, foram realizadas reuniões com a Secretaria de Agricultura do município e com as famílias produtoras, com a finalidade de interagir e explicar o papel da Unimontes no local, bem como a troca de saberes e conhecimento histórico, área local e a comunidade como um todo. Houve participação de 40 produtores rurais de várias comunidades no primeiro encontro de extensão relacionado à produção e manejo de palma forrageira. Houve participação de 60 produtores de várias comunidades na reunião referente às estratégias de suplementação. Detecta-se a importância da continuidade das palestras e orientações técnicas aos produtores da região com intuito de incrementar a produção animal/vegetal, a oferta de produtos de melhor qualidade e a fonte de renda dos envolvidos no sistema de produção.

Palavras-chaves: bovinos, extensão, Norte de Minas, semiárido, produção animal.

Abstract - The objective of this study was to provide guidance and encouragement to family farmers in the municipality of Espinosa regarding the use of technologies in a strategic way aimed at increasing milk and / or meat production throughout the year. The development of actions for

1Universidade Estadual de Montes Claros

2Prefeitura Municipal de Espinosa-MG

Monção et al, 84-92

3Instituto Superior de Educação Verde Norte (Favenorte) 
family producers in the region of Espinosa-MG was carried out from July 2017. Initially, meetings were held with the Municipal Department of Agriculture and with the producing families, with the purpose of interacting and explaining the the role of Unimontes in the place, as well as the exchange of knowledge and historical knowledge, local area and the community as a whole. There were 40 farmers from several communities participating in the first extension meeting related to the production and management of forage palm. There were 60 producers from several communities participating in the meeting on supplementary strategies. The importance of the continuity of the lectures and technical orientations to the producers of the region in order to increase the animal / vegetal production, the supply of products of better quality and the source of income of those involved in the production system is detected.

Keywords: cattle, extension, North of Minas, semi-arid, animal production.

\section{Introdução}

Fundada no ano de 1924, a cidade de Espinosa está localizada na região semiárida do Norte de Minas Gerais (Figura 1). A economia municipal tem oscilado consideravelmente ao longo dos 94 anos, sendo atualmente composta por setores industriais e, principalmente, pela produção agropecuária, maior responsável pelo produto interno bruto (IBGE, 2008).

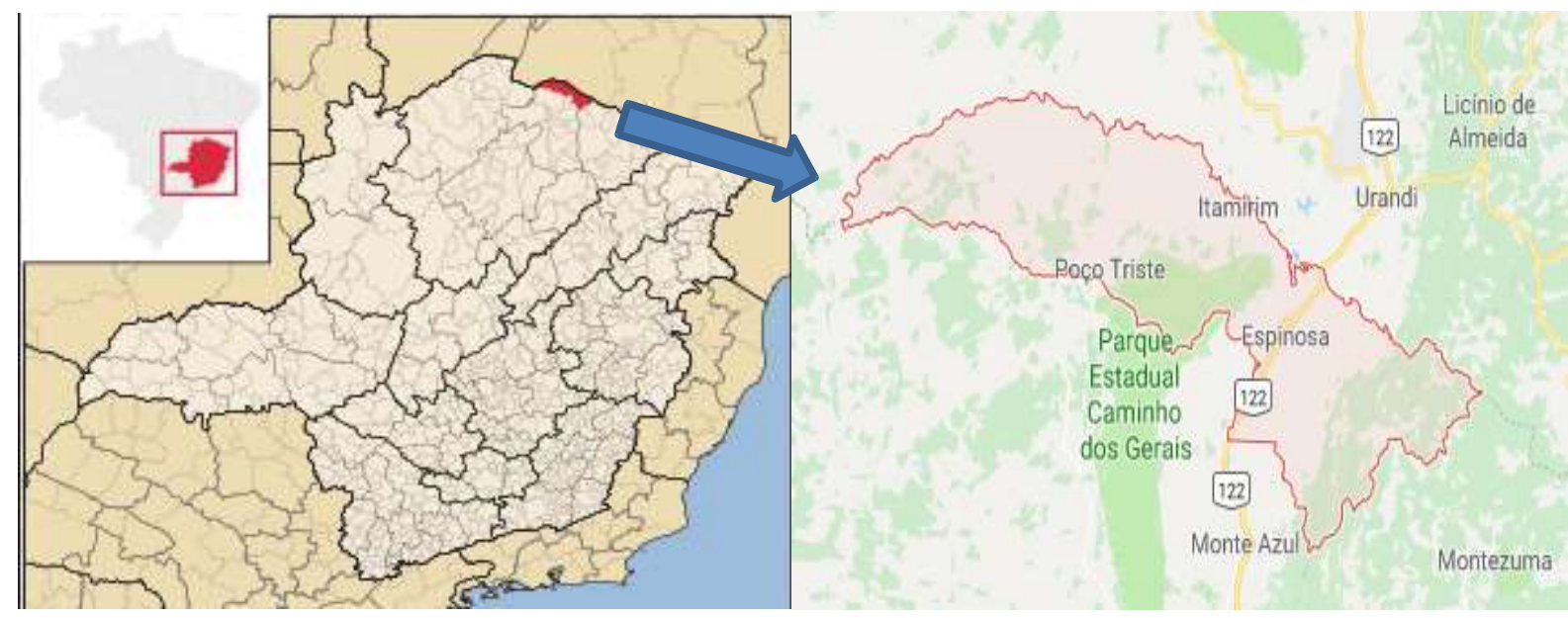

Figura 1. Localização geográfica do município de Espinosa, Minas Gerais ("Coordenadas geográficas Latitude: $14^{\circ} 55^{\prime}$ '33” S; Longitude: 42 49' 08" W). Fonte: Google.com.br; IBGE, 2008.

A produção agropecuária está concentrada, na maioria, de agricultores familiares que se destacam pela produção de carne, leite, ovos, derivados, culturas anuais e perenes. A produção animal baseia-se no uso de plantas forrageiras como fonte de nutrientes para os animais em sistemas de extrativismos, com médio/baixo ou nenhum nível tecnológico. Assim como no Brasil Central (SAMPAIO et al., 2017), a produção de forrageiras na região semiárida não é constante ao longo do ano (RIGUEIRA et al., 2018), o que reflete diretamente na oferta constante de produtos como leite 
e carne e outros no mercado consumidor. Alguns produtores distribuídos nas 92 comunidades do município de Espinosa conservam forragem na forma de silagem e/ou fenação para suplementar os animais nos períodos da seca. Mesmo assim, a produção animal é bastante afetada ao longo do ano, visto que, principalmente o manejo nutricional dos animais não é adequado por vários motivos que também incluem a falta de orientações técnicas e informações precisas. Normalmente, as orientações aos produtores ocorrem em lojas agropecuárias ou órgãos especializados do governo, mas mesmo assim, possivelmente devido à extensão territorial do município, há uma carência de acompanhamento técnico em nível de campo dos envolvidos com a produção de alimentos.

Desta forma, as ações extensionistas no meio rural é uma forma estratégica e de suma importância na transferência de tecnologias e conhecimentos geradas nos centros acadêmicos aos produtores rurais como relatados nos trabalhos de Oliveira et al., (2012; 2016; 2017) e Gabriel et al., (2015). Esses autores desenvolveram atividades extensionistas em diversas comunidades da região da Grande Dourados e Sul do Estado de Mato Grosso do Sul desde 2007 e reportaram avanços de desenvolvimentos significativos nas comunidades rurais e, sobretudo, para o município de Dourados. Essas metodologias de extensão rural e universitária propostas nos trabalhos de Oliveira et al., $(2012 ; 2016$; 2017) não são específicas, mas podem ser aplicadas e adaptadas em outras comunidades como as pertencentes ao município de Espinosa. As atividades extensionistas têm várias nas vantagens que se inicia desde a interação de alunos e professores das Universidades, entre si, e com os produtores rurais, bem como a tendência de maximização dos recursos ambientes de forma sustentável pelos produtores melhorando a renda e a fixação do homem no campo (Oliveira et al., 2017). Atualmente, uma das grandes preocupações existentes nos grandes Centros urbanos é quem será o produtor do futuro. Em cidades como Espinosa essa preocupação já existe nos órgãos governamentais, uma vez que esta e muitas outras cidades são muito dependentes da produção animal/vegetal como fonte de renda e de alimentos.

Sendo assim, a extensão rural tem papel fundamental na orientação dos produtores rurais, principalmente os que estão inseridas nas regiões semiáridas Brasileiras, devido às irregularidades das chuvas. Na região de Espinosa, por exemplo, a quantidade e a distribuição das chuvas nos últimos 5 anos tem provocado redução drástica na produção de alimentos, bem como nos custos de produção, visto que muitos produtores necessitaram de contratar serviços de perfuração de poços artesianos para irrigar as lavouras, adquirir maior volume de insumos e manter a produção animal/vegetal.

Com base no exposto, objetivou-se por meio de atividades extensionistas orientar e 
incentivar produtores da agricultura familiar do município de Espinosa quanto ao uso de tecnologias de forma estratégica visando à aumentar a produção de leite e/ou carne ao longo do ano.

\section{Material e Métodos}

O desenvolvimento das ações para os produtores familiares da região de EspinosaMG foi realizado a partir de Julho de 2017.

A princípio, foram realizadas reuniões com a secretaria de Agricultura do município e com as famílias com a finalidade de interagir e explicar o papel da Unimontes no local, bem como a troca de saberes e conhecer o histórico, área local e a comunidade como um todo. Posteriormente, foram realizadas reuniões participativas para planejamento de implantação e desenvolvimento de atividades, onde foram formados grupos mediante as atividades passíveis de serem implantadas. Palestras de cunho social e técnicas e cursos teórico-práticos foram desenvolvidas com o intuito de despertar o interesse das comunidades às novas possibilidades de produção e aprimorar as existentes. Durante as reuniões foram utilizados data show e folders, dentre outros recursos para transmitir a informação aos produtores. Todo material didático e de uso no campo, como sementes, entre outros, foram adquiridos através de lojas locais e auxílios de programas/projetos desenvolvidos pela Unimontes/Janaúba e instituições parceiras como secretaria de agricultura e pecuária de Espinosa juntamente com a EMATER local.

Dentre as atividades realizadas destacam-se as palestras oferecidas para todas as 92 comunidades envolvidas e oficinas realizadas mensalmente. Foram abordados assuntos sobre importância da mineralização e correção dos nutrientes das dietas dos animais durante o ano todo. Além disso, foi abordada a relevância do balanceamento da dieta dos animais, sobretudo para os com aptidão leiteira. Alguns produtores que não puderam de alguma forma participar das reuniões mensais no auditório da EMATER foram orientados em suas propriedades quanto ao uso das tecnologias e sanadas diversas dúvidas na área de produção animal/vegetal.

Foram utilizados folders e cartilhas sobre o manejo dos suplementos, assim como a importância da adaptação dos animais, como escolher o suplemento correto em função da análise do pasto. Os produtores também foram orientados em como fazer misturas múltiplas (suplementos concentrados) balanceadas na propriedade visando reduzir os custos com à alimentação.

Outro tema bastante discutido por meio de palestras e oficinas foi suplementação volumosa dos animais por meio na implantação e cultivo de palma forrageira. Foram utilizados folders e cartilhas sobre o manejo da palma, incluindo a escolha do local para plantio, preparo do 
solo, escolha das mudas, plantio, adubação, colheita e uso em dietas de ruminantes. A prefeitura local, por meio da secretaria de agricultura e pecuária, forneceu suporte para implantação de uma unidade demonstrativa de palma forrageira e capineiras em uma das comunidades como forma de oferecer mudas aos produtores envolvidos. As raquetes de Palma forrageira bem como as mudas de capineiras foram adquiridas na Fazenda experimental da Unimontes/ Janaúba.

As palestras e reuniões foram divulgadas por meio de contato verbal dos lojistas da região de Espinosa, cartazes e por distribuição de folders em locais estratégicos pela secretaria de agricultura e pecuária municipal.

\section{Resultados e Discussão}

No início, muitos produtores resistiram em participar das reuniões talvez por não acreditar nesse elo de extensão entre a Universidade e a Comunidade. Outros participaram com o intuito de conhecer melhor as ações do projeto, haja vista que essas ações eram uma novidade para o município. Mesmo assim, houve participação de 40 produtores de várias comunidades no primeiro encontro de extensão.

A principal limitação da produção animal na região de Espinosa consiste na oferta quantitativa de volumosos. Trabalhar com espécies forrageiras que conseguem produzir na região semiárida é o maior interesse e desafio dos produtores. Não somente a região de Espinosa, mas também todo o semiárido Norte Mineiro, há cinco anos (2012/2017) teve as precipitações abaixo da média $(700 \mathrm{~mm})$ e distribuída irregularmente, o que potencializou os efeitos do período da seca. Teve ano que a seca durou 10 meses.

Com isso, as ações de extensão com ênfase na produção de palma forrageira (Opuntia e Nopalea) ganharam destaque. A palma forrageira foi uma das poucas forrageiras existente no semiárido que conseguiu produzir em ambientes hostis de umidade e isso despertou interesse de muitos produtores de leite da região em participar das orientações técnicas.

No decorrer das atividades e orientações técnicas, os mesmos foram percebendo que a participação técnica é fundamental para contornar ou amenizar os entraves existentes sobre a produção animal/vegetal. Têm se verificado que $80 \%$ dos produtores que participaram das palestras e orientações em suas propriedades já estão cultivando até 0,3 hectares de palma como suporte forrageiro para os animais. Um entrave existente na propagação da palma foi quanto a disponibilidade quantitativa de raquetes isentas de pragas e doenças para serem distribuídas nas comunidades. Com isso, várias variedades de palma foram cultivadas na unidade demonstrativa 
visando fornece mudas para os produtores interessados. Atualmente, cerca de 80 produtores são atendidos pelas ações extensionistas no município de Espinosa em função da melhoria na produção animal e sustentabilidade no meio rural. A tendência é crescer ainda mais o cultivo de palma na região Norte de Minas devido à ações conjuntas de órgãos de pesquisa e Universidade em um grande projeto denominado de "Palmas para Minas" (FAEMG, 2018).

A palma forrageira é um suplemento volumoso de grande valia para os pecuaristas da região semiárida porque em sua composição apresenta em torno de $90 \%$ de umidade, o que reduz a ingestão de água pelos animais. Além disso, apresenta elevada quantidade de carboidratos não fibrosos na matéria seca. Mas não deve ser fornecida como volumoso exclusivo da dieta de ruminantes porque o teor de proteína bruta e fração fibrosa não atende os requerimentos dos animais, sendo, portanto, necessário fornecer associada com outros volumosos como silagens, feno e capineiras (tema de uma palestra sobre manejo de capineiras) (FERREIRA et al., 2012).

Outro tema discutido nas palestras foi quanto ao uso de suplementos concentrados e minerais. Houve participação de 60 produtores de várias comunidades na reunião referente às estratégias de suplementação. As orientações técnicas de manejo do pasto e dos suplementos foram de grande importância para os produtores porque foi abordado, dentre vários aspectos, a formulação dos suplementos para diferentes situações de manejo de pato e do pastejo na mesma região. Com isso, mais de 80 produtores foram orientados quanto ao manejo correto do pasto e a importância de suplementar os animais.

No decorrer das atividades e orientações técnicas, os produtores, assim como os órgãos públicos, foram percebendo que a participação técnica é fundamental para contornar ou amenizar os entraves existentes sobre a produção animal/vegetal e reduzir os custos de produção. Têm se verificado que $80 \%$ dos produtores que participaram das ações extensionistas reforçaram a importância e já estão mineralizando os animais e outros já estão programando para suplementar com concentrado de forma estratégica, ou seja, existe uma meta a ser alcançada. É impressionante as lacunas de conhecimentos existente no meio rural, onde produtores tem muito conhecimento prático, mas na maioria das vezes não conseguem crescer por não saber trabalhar ou organizar o conhecimento que têm. É nítido que a extensão rural e/ou universitária é fundamental no acompanhamento e orientação dos envolvidos no meio rural conforme diversos trabalhos de Oliveira et al., (2012; 2016) e Gabriel et al., (2015) em comunidades localizadas no Sul do Mato Grosso do Sul.

Outro ponto relevante com as ações de extensão na região de Espinosa é que nem 
todos os produtores das comunidades estarão envolvidos e aptos em receber as orientações técnicas. Nesse sentido, é importante selecionar, naturalmente, os que têm maiores interesse e trabalhar neles quanto ao uso da técnica em determinada necessidade. Isso faz com que outras pessoas se envolvam com as atividades porque veem o crescimento do vizinho. Isso ocorreu no decorrer do desenvolvimento das palestras com o seguinte questionamento: "a terra é a mesma, o rio é o mesmo, se deu certo na fazenda do vizinho dará certo na minha também". Nesse contexto, os envolvidos com a extensão no meio rural ganham uma chance de dialogar com vários produtores que antes não disponíveis e transmitir a mensagem correta.

Mais de 60 pessoas produtores participaram da palestra sobre manejo de capineiras para região. Com a implantação de queijeiras no município local e vizinho, muito produtores passaram a mudar o sistema de produção de animais de corte para leite. Logo, muitas capineiras, principalmente Pennisetum purpureum cv Napier e Mineirão foram implantadas como suporte forrageiro volumoso para os animais. No entanto, déficit de manejo era uma realidade, o que reforçava a importância da extensão rural. Nas palestras foram abordados diversos cultivares com potencial de formação das capineiras, manejo de corte, adubação, irrigação e fornecimento aos animais. Um destaque apresentado aos produtores foi o capim elefante cultivar BRS Capiaçú lançado no final do ano de 2015 pela EMBRAPA (PEREIRA et al., 2016). Esse cultivar difere dos demais Pennisetum purpureum por apresentar produção de massa seca 30\% superior aos demais cultivares da mesma espécie, quando bem manejado. Desta forma, destaca a importância das ações extensionistas nas comunidades do município por sucumbir à produção animal/vegetal, melhorar a renda dos produtores e reduzir o êxodo rural. A produção de forma sustentável no meio rural é uma forma dos filhos dos produtores que outrora pensavam em mudar se para os centros urbanos permaneceram no campo e garantir a produção de alimentos para o futuro. Outro destaque das ações conjuntas entre o meio acadêmico e rural foi à participação das mulheres nas palestras. A presença das queijeiras na região, associada ao modelo de pagamento mensal dos produtores de leite despertaram as mulheres em participar diretamente das atividades no campo e ter renda. Essa ocasião exigiu das mesmas a busca por conhecimento e atualização de assuntos relevante de produção animal.

\section{Conclusão}

Detecta-se a importância da continuidade das palestras e orientações a técnicas aos produtores da região com intuito de incrementar a produção animal/vegetal, a oferta de produtos de 
melhor qualidade e a fonte de renda dos envolvidos.

\section{Agradecimentos}

À Prefeitura Municipal de Espinosa, Unimontes, Emater Regional de Janaúba e Espinosa, FAPEMIG e Capes pelo suporte financeiro e concessão de bolsa de estudo.

\section{Referências}

«DIVISÃO TERRITORIAL DO BRASIL». Divisão Territorial do Brasil e Limites Territoriais. Instituto Brasileiro de Geografia e Estatística (IBGE). 1 de julho de 2008. Consultado em 14 de Maio de 2018

FAEMG- Palmas para Minas. http://www.sistemafaemg.org.br/Noticia.aspx? Code $=13992 \&$ Portal $=1 \&$ PortalNews $=1 \&$ ParentCode $=139 \&$ ParentPath=None $\&$ ContentVersion $=\mathrm{R}$. Acessado em Maio de 2018.

FERREIRA, M.A., BISPO, S.V., ROCHA FILHO, R.R., URBANO, S.A., COSTA, C.T.F. The use of cactus as forage for dairy cows in semi-arid regions of Brazil. In: PetrKon valina.(Org.), Organic Farming and Food Production. InTech, South Bohemia, 2012. p. 1-22.

GABRIEL, A.M.A.; SOUZA, R.; OLIVEIRA, E.R.; ROSSINI, L.C.; MONÇÃO, F.P.; RAMOS, M.B.M.; GIMENES, L.S.; PEREIRA, T.L.; SILVA, E.C.P. Orientação em apiários noAssentamento Amparo, Dourados-MS. Revista online de Extensão e Cultura Realização, v. 2, n.3, p. 36-41, 2015.

OLIVEIRA, E.R.; GABRIEL, A.M.A.; MONÇÃO, F.P.; FARIAS, M.F.L.; PEIXOTO, P.P.P.; RAMOS, M.B.M.; MOURA, L.V.; PEREIRA, T.L.; GANDRA, J.R.; SANTOS JUNIOR, E.A. Extensão universitária como estratégia de desenvolvimento na Comunidade Quilombola de Dourados/MS. Revista online de Extensão e Cultura Realização, v. 3, n.1, p. 35-44, 2016 b.

OLIVEIRA, E.R.; MONÇÃO, F.P.; RAMOS, M.B.M.; GABRIEL, A. M. A.; FARIAS, M.F.L.; MOURA, L.V. Práticas extensionistas no desenvolvimento sustentável da comunidade quilombola de dourados, mato grosso do sul. Em Extensão, v. 11, n. 2, p. 82-95, 2012.

Oliveira, E.R.; Muniz, E.B.; Gabriel, A.M.A.; Monção, F.P.; Gandra, J.R.; Gandra, E.R.S.; Pereira, T.L.; Silva, M.S.J.; Gouvea, W.S.; Carmo, A.A.; Pedrini, C.A.; Becker, R.A.S. Produção de feno orgânico como estratégia de suplementação volumosa para ruminantes produzidos nas comunidades rurais de mato grosso do sul. Revista online de Extensão e Cultura Realização, v.4, n.8, p-87-97, 2017.

PEREIRA, A.V.; LEDO, F.J.S.; MORENZ, M.J.F.; LEITE, J.L.B.; DOS SANTOS, A.M.B.; MARTINS, C.E.; MACHADO, J.C. BRS Capiaçú: cultivar de capim-elefante de alto rendimento para produção de silagem. Comunicado Técnico EMBRAPA, Juiz de Fora, MG, Outubro, 2016. ISSN 1678-3131.

RIGUEIRA, J.P.S.; MONÇÃO, F.P.; SALES, E.C.J.; REIS, S.T.; BRANT, L.M.S.; CHAMONE, 
J.M.A.; ROCHA JÚNIOR, V.R.; PIRES, D.A.A. Fermentative profile and nutritional value of elephant grass silage with different levels of crude glycerin. Semina: Ciências Agrárias, v. 39, n. 2, p. 833-844, 2018.

SAMPAIO, R.L.; RESENDE, F.D.; REIS, R.A.; OLIVEIRA, I.M.; CUSTÓDIO, L.; FERNANDES, R.M.; PAZDIORA, R.D.; SIQUEIRA, G.R. The nutritional interrelationship between the growing and finishing phases in crossbred cattle raised in a tropical system. Tropical Animal Health Production, v.49, n.1, p.1015-1024, 2017. 